\title{
Rotary-screw systems for rotary kilns
}

\author{
Aleksandr Sekisov $^{1 *}$ and Georgy Serga ${ }^{2}$ \\ ${ }^{1}$ Kuban State Technological University, Krasnodar, Moscowskaya str., 2 \\ ${ }^{2}$ Kuban State Agrarian University named after I.T. Trubilin, 350044, Krasnodar, Kalinina str., 13.
}

\begin{abstract}
The proposed paper examines rotary-screw systems for rotary kilns in the production of expanded clay. To reduce the size, reduce weight, increase productivity, simplify operation, reduce energy consumption in the production of expanded clay, the shell is made screwshaped and mounted horizontally. Technical solutions protected by six patents of the Russian Federation are proposed, the structures of the shells of rotary kilns are shown, which, in comparison with the known structures of similar purpose, are made screw-shaped with internal spiral grooves. The dependence is proposed for determining the speed of movement of expanded clay pellets in a screw-shaped shell of a rotary kiln. A classification of rotary-screw systems for the production of expanded clay was developed.
\end{abstract}

\section{Introduction}

In the production of expanded clay, powerful rotary kiln with a length of $20-50 \mathrm{~m}$ and with a diameter of $1.5-3.5 \mathrm{~m}$ (at a temperature of $1300^{\circ} \mathrm{C}$ for $30-60$ minutes) containing a lined cylindrical shell mounted on roller supports with a sector cut with opening angle of $150-160^{\circ}$ in the high-temperature zone with installed stationary burners are used, and in the cooling zone, an additional, at least one sector cut is formed, in which a collector for cooling air supply, burners, and a drive are placed. The disadvantages of such kilns are, as a rule, not only the failure to provide the necessary heat treatment conditions, the long length of the kiln shell to ensure complete rolling of the pellets to improve the quality of the expanded clay, but also limited technological capabilities, as well as the fact that the kiln shell is set at an angle to the axis of rotation, requires additional devices to keep the entire mass of the rotating kiln in this inclined state. This complicates the operation and increases costs [1-7].

These disadvantages can be eliminated by creating and manufacturing a screw-shaped shell along the outer surface of its perimeter and horizontal arrangement of its axis of rotation, which allows increasing the speed of its rotation and simplifies the operation of the kiln due to the absence of a slope of a screw-shaped shell. The proposed paper shows not only new technical solutions of the authors in the development of rotary-screw systems for rotary kilns based on screw-shaped shells but also developed methods of computer modeling, technology of assembly, and calculation of screw-shaped shells.

\footnotetext{
${ }^{*}$ Corresponding author: $\underline{\text { alnikkss@gmail.com }}$
} 


\section{Rotary kiln for firing expanded clay}

\subsection{Description of construction and operation}

The proposed rotary kiln for firing expanded clay is presented in Figure 1 [8].

The proposed rotary kiln for firing expanded clay works as follows.
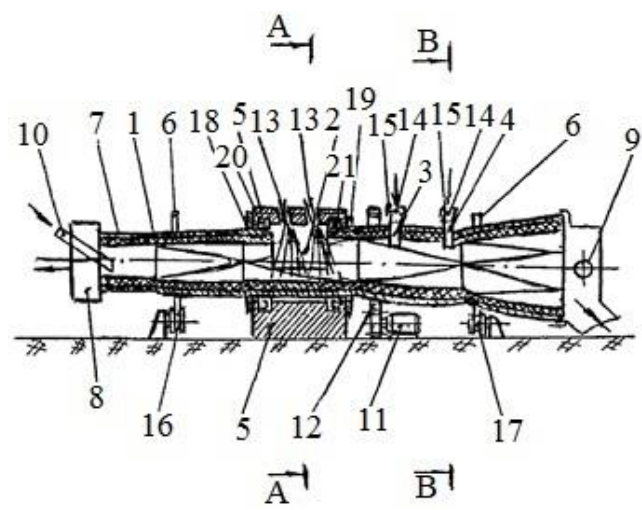

$\underline{\mathrm{A}-\mathrm{A}}$

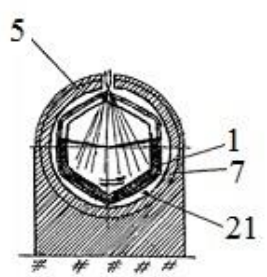

$\underline{\mathrm{B}-\mathrm{B}}$

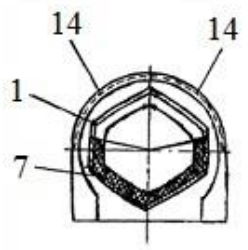

Fig. 1. Rotary kiln for firing expanded clay, a general view:1 - conical screw-shaped shell; 2, 3, 4 - sector cuts; 5 - rocker; 6 - rims; 7 - refractory masonry; 8,9 - exhaust devices; 10 chute; 11 - drive; 12 - girth gear; 13 - burner devices;14 - pipelines; 15 - gate valves; 18, 19 ring overlays; 20,21 - bush sleeves.

The raw pellets at chute 10 enter the zone of heating of the conical screw-shaped shell 1 , where they are heated to $11000^{\circ} \mathrm{C}$ due to the heat of the combustion products sucked from the swelling zone by the exhaust device 8 . In a conical screw-shaped shell 1 , the layer of firing pellets moves due to the rotation of the conical screw-shaped shell 1 with rims 6 on roller bearings 16 and 17 using the tilting mechanism 1, which consists of the drive 11 and the girth gear 12 fixed on the conical screw-shaped shell 1 .

From the heated zone, the pellets enter the expansion zone, where through the sector cut 2 , hot combustion products obtained with the help of burning devices 13 are directed right on the pellet layer. Through the sector cut 3 and the gate valve 15, along the pipeline 14, redox gas environment, which improves the quality of the pellets, is supplied to the burning zone.

Through sector cut 4 , cooling air is supplied to the cooling zone, or gases are drawn from it, as a result of which the pellets are rapidly cooled. In order to improve the cooling of the pellets, additional cuts along the length of the kiln can be made. Excessive combustion products are removed from the conical screw-shaped shell 1 by an exhaust device 9 located on the discharge side of the finished pellets.

\subsection{Computer modeling of screw-shaped shells and the development of their manufacturing technology}

Figure 2 presents, for example, the results of modeling of some screw-shaped shells, using the "Compass-3D" software package. 


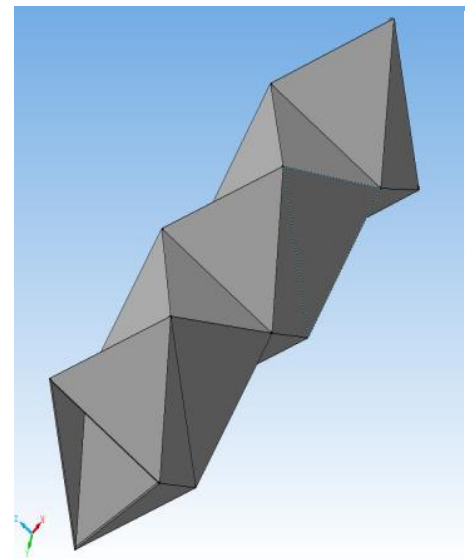

a)

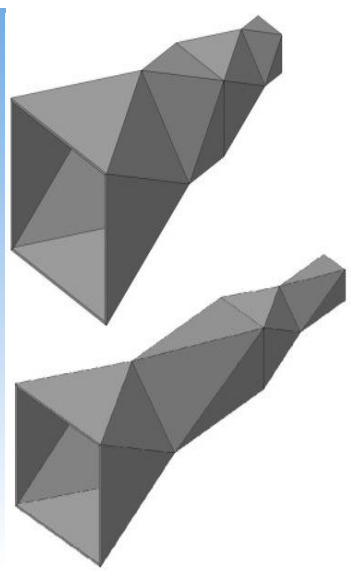

b)

Fig. 2. Screw-shaped shells: a) conventionally cylindrical shape, b) conventionally conical shape.

And then, after modeling, in accordance with the proposed method, the design study of the screw-shaped shell is carried out, and the technology of its manufacture and assembly is developed, as in Figure 3, Figure 4, Figure 5 [8], in accordance with which trapezoidshaped strips are made with notches at an angle of $60^{\circ}$ (Fig. 3 ).



Fig. 3. One of the strips, front view.

These strips are twisted around the horizontal axis (Fig. 4).

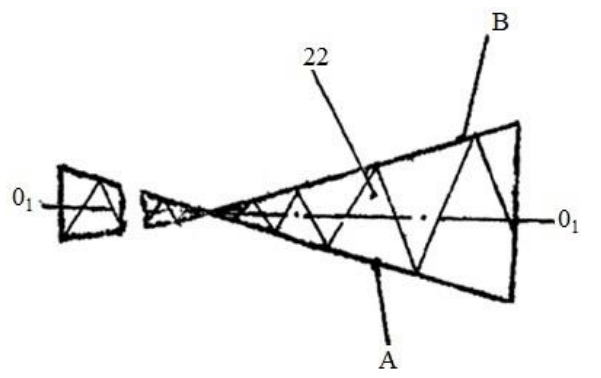

Fig. 4. View of the strip after twisting its ends relative to longitudinal axis.

Then the twisted strips are rolled up around the tapered mandrel (Fig.5) 

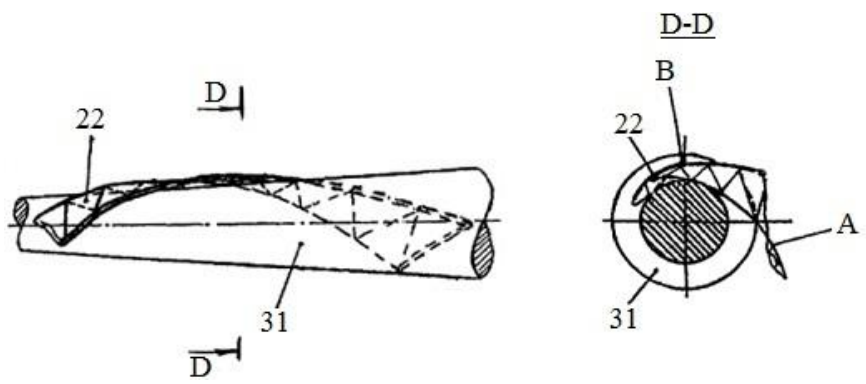

Fig. 5. View of the strip after bending it on a tapered mandrel.

Then, three, four, five, six and more strips deformed by this method are connected by the known methods along the side edges A and B. Thus, a screw-shaped shell is made, as for example in Fig. 6
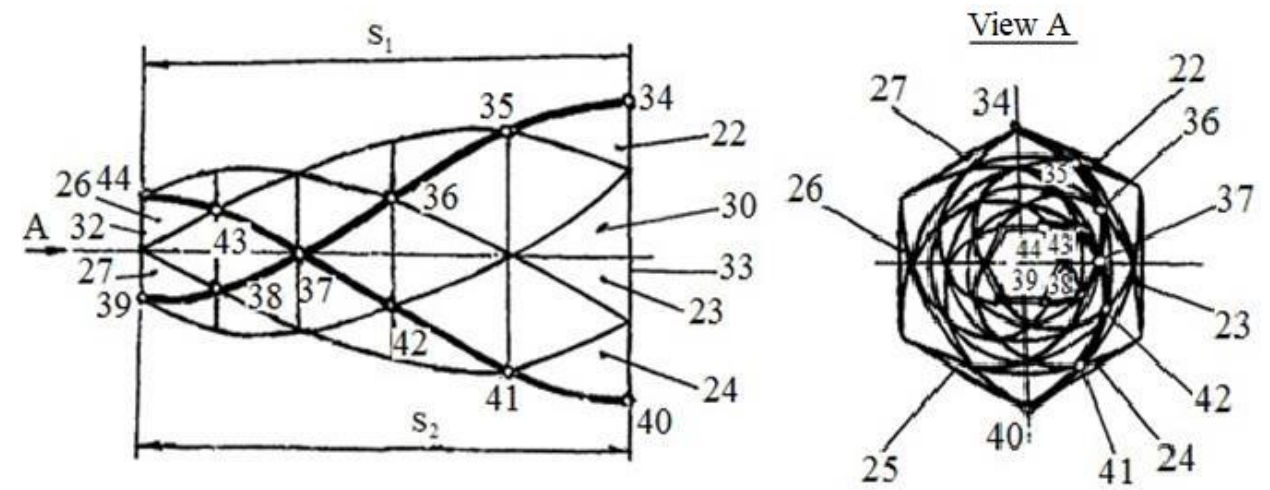

Fig. 6. Conical screw-shaped shell, front view.

For the introduction into production, we have developed technologies for the assembly of screw-shaped shells and for mass production.

\subsection{Development of methods for calculating screw-shaped shells}

The main parameters required for the design of rotary kilns based on screw-shaped shells, in addition to the speed of the longitudinal movement of the expanded clay pellets and the length, are the diameters of the (outer and inner) screw-shaped shell.

As a result of the research on the design features of screw-shaped shells, dependences have been obtained that can be used to determine:

Outer diameter of conventionally cylindrical screw-shaped shells:

$$
\mathrm{D}=\mathrm{k}_{1} \cdot \mathrm{a}_{1},
$$

where $\mathrm{a}_{1}$ - the width (side) of the element from which the cylindrical screw-shaped shell is assembled; $\mathrm{k}_{1}$ - correction factor.

Inner diameter of cylindrical screw-shaped shells:

$$
\mathrm{d}=\mathrm{m}_{1} \quad \mathrm{a}_{1},
$$

where $\mathrm{m}_{1}-$ correction factor.

Outer diameter of conventionally cylindrical screw-shaped shells:

$$
\text { For the first section } D_{1}=k \cdot a_{2}
$$




$$
\begin{aligned}
& \text { for the second section } D_{2}=k_{2} \cdot\left(a_{2}+c\right) \\
& \text { for the third section } D_{3}=k_{2} \cdot\left(a_{2}+2 \cdot c\right) \\
& \text { for the fourth section } D_{4}=k_{2} \cdot\left(a_{2}+3 \cdot c\right)
\end{aligned}
$$

and etc.

where $\mathrm{k}_{2}$ - correction factor; $\mathrm{a}_{2}$ - the width of the element from which the cylindrical screw-shaped shell is assembled; c - correction factor.

Diameter of internal cross section of conical screw-shaped shell:

$$
\begin{aligned}
& \text { For the first section } d_{1}=m_{2} \cdot a_{2}, \\
& \text { for the second section } d_{2}=m_{2} \cdot\left(a_{2}+c\right) \text {, } \\
& \text { for the third section } d_{3}=m_{2} \cdot\left(a_{2}+2 c\right), \\
& \text { for the fourth section } d_{4}=m_{2} \cdot(a+3 c),
\end{aligned}
$$

and etc.

where $\mathrm{m}_{2}$ - correction factor.

It was established that depending on the dimensions of the screw-shaped shell, filling factors, the geometry of the screw-shaped shell, and a number of other factors, a greater or lesser amount of pellets of expanded clay is processed in a mixed waterfall-avalanche mode.

As the analysis of these mathematical models has shown, such problems (the model of a continuous medium, the energy model, the model of a closed medium with the stochastic process of collisions of expanded clay pellets) cannot be solved analytically. Therefore, the model of movement of expanded clay pellets as a material point of mass $\mathrm{m}$ was considered, and a system of differential equations was obtained in the following form [9]:

$$
\begin{gathered}
\mathrm{m} \cdot\left(\rho-\rho \cdot \varphi^{2}\right)=\mathrm{F}_{\rho} \\
\mathrm{m} \cdot(\rho \cdot \varphi+2 \cdot \rho \cdot \varphi)=\mathrm{F}_{\varphi},
\end{gathered}
$$

After simplifications, for example, $\rho=r=r_{c p(a)}=$ const, transformations by known methods and using the properties of screw-shaped shells $j=$ const - constancy of the angle of inclination of the screw-shaped lines to the longitudinal axis (axis of rotation) for the screw-shaped shells, an equation is obtained for determining the speed of the longitudinal movement of expanded clay pellets $\mathrm{V}$ :

$$
\mathrm{V}=\mathrm{r} \cdot \tan \mathrm{j} \cdot \omega+\mathrm{C},
$$

where $\omega$ - angular rotation speed of the screw-shaped shell;

$\mathrm{C}-\mathrm{a}$ constant that expresses the characteristics of the process, for example, the fill factor of the inner cavity of the screw-shaped shell $\mathrm{K}_{\mathrm{v}}$.

Therefore, introducing the constant $\mathrm{G}$ into equation (2):

$$
\mathrm{G}=\mathrm{r} \cdot \tan \mathrm{j}(\mathrm{mm})
$$

we will get the formula to determine the speed of the longitudinal movement of expanded clay pellets:

$$
\mathrm{V}=\mathrm{G} \cdot \omega+\mathrm{C}(\mathrm{mm} / \mathrm{s}),
$$

Thus, under the action of gravitational forces and the angle of repose, the expanded clay pellets move at certain angles to each other, to the opposite walls of the rotating screwshaped shell and move in the direction of discharge. At the same time, the movement of expanded clay pellets with a large amplitude and low frequency created by a rotating 
screw-shaped shell is superimposed by the movement of expanded clay pellets with a small amplitude and high frequency of their collisions formed by the reflection of their flows by opposite inner walls of the shell of various configurations. Since the surface of the screwshaped shell is continuous, the process of the movement of subsequent portions of expanded clay pellets, which rise up and fall down while moving at different angles, is also continuous. Since the spiral grooves of the inner surface of the screw-shaped shell are angled to each other, each portion of the expanded clay pellets interacts with each other and with the walls of the screw-shaped shell, which increases the intensity of the technological process and expands technological capabilities. As a result of such a constructive design of a screw-shaped shell of a rotary kiln, the range of changes in the resulting displacement vectors of expanded clay pellets has been significantly expanded. Therefore, each expanded clay pellet moves along different direction vectors, which provides a greater probability of collisions, not only at the initial moment of their separation from the walls of the screwshaped shell, where they have a certain amount of kinetic energy and move with large kinetic energy along large trajectories, but also when they touch with opposite internal walls of various configurations, which provides an intensification of the technological process.

When summarizing and describing the experimental data, the dependences of the speed of the longitudinal movement of the expanded clay pellets in the screw-shaped shells can definitely be described by a polynomial $\mathrm{P}_{4}$ :

$$
\mathrm{P}_{4}=\mathrm{a}_{0} \mathrm{x}^{4}+\mathrm{a}_{1} \mathrm{x}^{3}+\mathrm{a}_{2} \mathrm{x}^{2}+\mathrm{a}_{3} \mathrm{x}+\mathrm{a}_{4},
$$

Thus, the empirical dependence for determining the speed of longitudinal movement of expanded clay pellets in the screw-shaped shells is:

$$
\mathrm{V}=\mathrm{A} \cdot\left(\omega^{4}+\mathrm{b}_{1} \cdot \omega^{3}+\mathrm{b}_{2} \cdot \omega^{2}+\mathrm{b}_{3}+\mathrm{b}_{4}\right)
$$

where $\mathrm{A}$ is a coefficient depending on the operating conditions of the screw-shaped shell (geometrical dimensions, mass of expanded clay pellets, degree of filling of the screwshaped shell $\left.-\mathrm{K}_{\mathrm{v}}\right)$;

$\omega$ - angular rotation speed of the screw-shaped shell;

$b_{1}, b_{2}, b_{3}, b_{4}-$ coefficients characterizing the features of the designs of screw-shaped shells.

\section{Conclusions}

Among the most important conclusions of theoretical and experimental research are the following:

1) The rotation speed of the screw-shaped shell has the greatest influence on the speed of movement of the expanded clay pellets.

2) A significant effect on the speed of movement of the expanded clay pellets revealed in the filling factor of the internal cavity of the screw-shaped shell. For each form of the screw-shaped shell, there is a certain optimum filling factor when the speed of movement of the expanded clay pellets is greatest.

3) The screw-shaped shell design has a significant effect on the speed of movement. With an increase in the bore area of the screw-shaped shell, the speed of the longitudinal movement of the expanded clay pellets increases, approximately in a linear relationship.

5) The mass of expanded clay pellets does not have a significant effect on the speed of their movement.

6) The technology for the assembly of the screw-shaped shells for single and mass production are proposed. 
7) In order to use the research results in production practice, mathematical dependencies were obtained to determine the calculated technical characteristics of the screw-shaped shell.

Thus, the paper systematizes the results of many years of the authors' research in the development of rotary-screw systems for rotary kilns. The use of the proposed structures of the screw-shaped shells, in comparison with the known structures of similar purpose, significantly improves performance, reduces the size, weight of the kilns and energy consumption, by making them hollow, with side walls mounted from individual strips or plates of various geometric shapes, with the formation of broken or smooth spiral surfaces and spiral grooves inside the screw-shaped shells and their horizontal arrangement. As a result of the performed work, a classification of rotary-screw systems for the production of expanded clay was developed, which is presented in Figure 7.

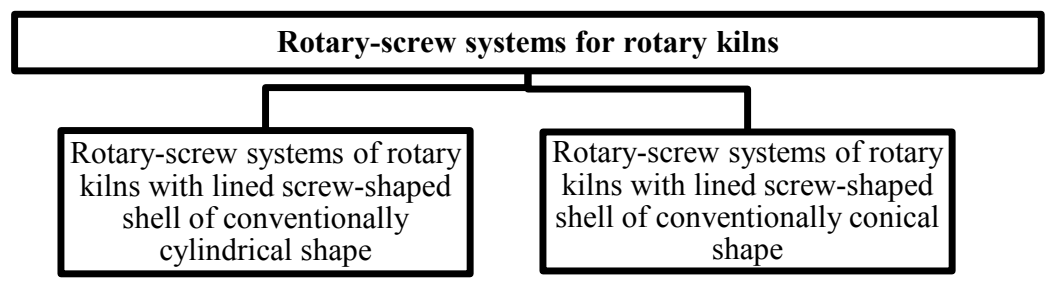

Fig. 7. Classification of rotary-screw systems for the production of expanded clay.

Technical solutions protected by six patents of the Russian Federation (attached in the list of references [8]) and the relationship to determine the speed of movement of the expanded clay pellets in kilns are proposed.

\section{References}

1. T.F. Mokoena, M.D. Madyira, T.O. Babarinde, S.A. Akinlabi, IOP Conf. Series: Materials Science and Engineering 413, 012071 (2018) https://doi:10.1088/1757899X/413/1/012071

2. A.N. Sekisov, O.G. Degtyareva, N.V. Samsonova and M.N. Grigoryan, International conference on Construction and Architecture: theory and practice of industry development (CATPID-2018), Trans Tech Publications 931, 1210-1213 (2018) https://doi:10.4028/www.scientific.net/MSF.931.1210

3. Q. Yin, Q. Chen , W.-J. Du , X.-L. Ji , L.Cheng, International Journal of Heat and Mass Transfer 93, $1-8(2016)$

https://doi.org/10.1016/j.ijheatmasstransfer.2015.08.078

4. S.N. Vijayan, S. Sendhilkumar, International Journal of Engineering Innovation \& Research 3, 3 (2014)

5. V.A. Lebedev, G.V. Serga, A.V. Khandozhko, IOP Conf. Ser.: Mater. Sci. Eng. 327, 042062 (2018) doi: 10.1088 / 1757-899X / 327/4/042062.

6. E.V. Lutsenko, G.V. Serga, Polythematic network electronic scientific journal of the Kuban State Agrarian University (Scientific journal of KubSAU) 07(121), 68 - 115 (2016)

7. G.V.Serga, A.Yu. Marchenko, Polythematic network electronic scientific journal KubGAU (Scientific journal KubGAU) 03(127), 1261703005 (2017)

8. V.D. Taratuta, G.V. Serga, Kuban State Agrarian University 24, 2014124770/02 (2015)

9. G. Korn, Handbook of mathematics (Science, Moscow, 1973) 